Special issue of the 3rd International Conference on Computational and Experimental Science and Engineering (ICCESEN 2016)

\title{
Experimental Analysis of Titanium Dioxide Synthesis from Synthetic Rutile Waste using a Moderate Acid Concentration and Temperature
}

\author{
H. Ahmad Mukifza, H.B. Awang*, S. Yusof and E.M. Farid \\ University Malaysia Sabah, Faculty of Engineering, Kota Kinabalu, 88400 Sabah, Malaysia
}

\begin{abstract}
The present study is to clarify the present influences of acid concentration and temperature of caustic hydrothermal method on extracting the titanium dioxide $\left(\mathrm{TiO}_{2}\right)$ from synthetic rutile waste. In this experimental work, the caustic hydrothermal method comprises two processes: a decomposition and the sulphate process. The extracted titanium is characterized by using a electron dispersive X-ray spectroscopy to specify its chemical composition, field emission scanning electron microscope to determine the morphology and particle size, and lastly it is the X-ray diffraction to analyse the crystallinity of extracted titanium. In this study, we found that both acid concentration and temperature affected the $\mathrm{TiO}_{2}$ growth while the calcination process could improve the crystallinity of extracted titanium.
\end{abstract}

DOI: 10.12693 /APhysPolA.132.833

PACS/topics: synthetic rutile, titanium dioxide, caustic hydrothermal, sodium titanate

\section{Introduction}

$\mathrm{TiO}_{2}$ is one of the transition metal oxides and semiconductors with a unique characteristics, good photocatalytic behavior comparing to the pure metal. This superb photocatalyst behavior of $\mathrm{TiO}_{2}$ causes so many researchers all over the world interested to extract and trying to enhance its photocatalytic behaviour by improvise the extracting method since 1923 until now [1]. The main mineral use to produce a $\mathrm{TiO}_{2}$ are ilmenite, rutile raw materials and leucoxene [2]. There are so many extracting $\mathrm{TiO}_{2}$ methods reported by previous researchers such as the template-assisted method [3], electrochemical anodic oxidation method [4], fiber laser ablation [5], modified molten salt process [6, 7], hydrothermal treatment $[8,9]$ and etc. In this study, we choose the caustic hydrothermal method as reported by many researchers [8-12]. Due to $\mathrm{Ou}$, Paulus, and Mahdi et al., the caustic hydrothermal method can produce the $\mathrm{TiO}_{2}$ in the powder form and this method can be simply modified in order to achieve a better characteristics of titanium powders $[8,10,11]$. The importance of this experimental study of analysis is trying to understand the effect of certain parameters to extract the optimum growth of nano $\mathrm{TiO}_{2}$ from ilmenite waste.

The effect of moderate temperature and acid concentration on the caustic hydrothermal method were analysed by identifying their chemical composition, morphology and particle size and lastly, their crystallinity phase by using electron dispersive X-ray (EDX), field emission scanning electron microscope (FESEM) and X-ray diffraction (XRD), respectively This study will determine which parameters need to be controlled in order

\footnotetext{
*corresponding author; e-mail: huzaikha.ums@gmail.com
}

to achieve a highest purity of caustic thermal synthesis $\mathrm{TiO}_{2}$ nanoparticles.

\section{Materials and methods \\ 2.1. Decomposition process}

The starting raw material, synthetic rutile waste which was getting from mining product is the derivation product from the ilmenite waste. The $100 \mathrm{~g}$ synthetic rutile waste was decomposed with $200 \mathrm{~g}$ sodium hydroxide pellets, $\mathrm{NaOH}$ at $550^{\circ} \mathrm{C}$ for $3 \mathrm{~h}$. The product was then washed with deionized water. The formed $\mathrm{Na}_{2} \mathrm{TiO}_{3}$ was then collected by filtration and dried at room temperature. The formation process of $\mathrm{Na}_{2} \mathrm{TiO}_{3}$ compound via this decomposition process can be represented as below

$$
\mathrm{TiO}_{2}+2 \mathrm{NaOH} \rightarrow \mathrm{Na}_{2} \mathrm{TiO}_{3}+\mathrm{H}_{2} \mathrm{O} .
$$

\subsection{Sulphate process}

Three $50 \mathrm{ml}$ florence flask, digital hot plate stirrer, and a reflux condenser were used in this sulphate process. A dried $\mathrm{Na}_{2} \mathrm{TiO}_{3}$ was mixed with three different acid concentrations 1,2 , and $3 \mathrm{M}$ and then heated simultaneously with $70{ }^{\circ} \mathrm{C}, 80^{\circ} \mathrm{C}$ and $90^{\circ} \mathrm{C}$ temperature for $4 \mathrm{~h}$. After the treatment, the white residue obtained was then washed with deionized water and ethyl alcohol. The $\mathrm{TiO}_{2}$ was collected by filtration and dried at $80^{\circ} \mathrm{C}$ for $4 \mathrm{~h}$. Lastly, the formed $\mathrm{TiO}_{2}$ powder was crushed and ground into fine powder using a metal mesh net.

\subsection{Titanium dioxide, $\mathrm{TiO}_{2}$ characterization}

In this study, all extracted $\mathrm{TiO}_{2}$ will undergo three characterization: EDX, FESEM, and XRD. EDX characterization (EDAX International DX-95 EDX spectrometer) was conducted to analyse the chemical composition of the sample. Three readings have been taken to get an average of extracted titanium wattage. The FESEM was used to identify the morphology / growth of 
extracted $\mathrm{TiO}_{2}$ and also to measure the particle size of extracted $\mathrm{TiO}_{2}$. XRD analysis was performed to identify the crystallinity of extracted $\mathrm{TiO}_{2}$. Besides that, these XRD results also show us the crystalline phase of extracted $\mathrm{TiO}_{2}$ (anatase or rutile phase) with measurable crystallite size.

\section{Results and discussion \\ 3.1. EDX result}

Table I shows the wettage of extracted titanium for 1,2 , and $3 \mathrm{M}$ acid concentration treated at $70^{\circ} \mathrm{C}, 80^{\circ} \mathrm{C}$ and $90^{\circ} \mathrm{C}$ temperature during $4 \mathrm{~h}$ of sulphate process. For the $1 \mathrm{M}$ samples, the values of titanium wettage are $81.14 \%, 88.17 \%$, and $94.72 \%$ while for the $2 \mathrm{M}$ samples are $83.09 \%, 94.48 \%$, and $96.44 \%$ after treating at $70{ }^{\circ} \mathrm{C}, 80^{\circ} \mathrm{C}$ and $90^{\circ} \mathrm{C}$ temperature, respectively. For the $3 \mathrm{M}$ samples, the value of titanium wettage also increases with $87.10 \%, 97.81 \%$ and $98.59 \%$, respectively. The result shows that the higher the temperature, the higher the wettage of extracted titanium. The result was similar to that reported in Zhang research $[13,14]$. In this temperature test parameter, we decide to choose $80^{\circ} \mathrm{C}$ temperature to be fixed in the next experimental works because from Table I, we can see that the wettage for 1, 2, and $3 \mathrm{M}$ samples is highly increased at $80^{\circ} \mathrm{C}$ treatment compared to the $70^{\circ} \mathrm{C}$ and only shows a bit increment during the $90^{\circ} \mathrm{C}$.

TABLE I

Extracted titanium [wt\%] under varies temperature for 1,2 , and $3 \mathrm{M}$ acid concentration of sulphate process examined by EDX (treatment time $=4 \mathrm{~h}$.

\begin{tabular}{c|c|c|c}
\hline \hline $\begin{array}{c}\text { Temperature } t\left[{ }^{\circ} \mathrm{C}\right] \\
\text { acid concentration }\end{array}$ & 70 & 80 & 90 \\
\hline $1 \mathrm{M}$ & 81.14 & 88.17 & 94.72 \\
$2 \mathrm{M}$ & 83.09 & 94.48 & 96.44 \\
$3 \mathrm{M}$ & 87.10 & 97.81 & 98.59
\end{tabular}

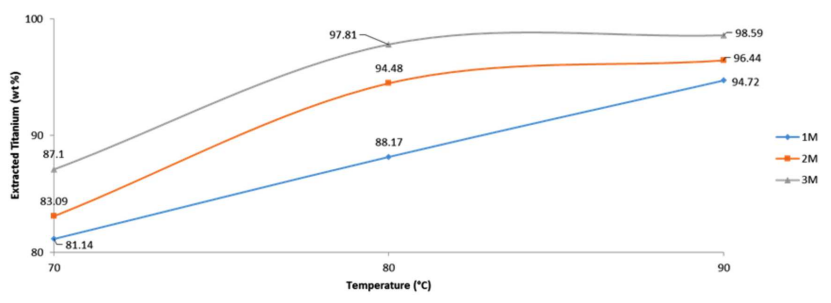

Fig. 1. Extracted titanium [wt\%] of 1, 2, and $3 \mathrm{M}$ treated samples versus temperature examined by EDX.

Figure 1 is the graph of the wettage of extracted $\mathrm{TiO}_{2}$ versus the temperature for the 1,2 , and $3 \mathrm{M}$ samples. This graph clearly shows the effect of acid concentrations on titanium extraction under varying temperature at $4 \mathrm{~h}$ treatment time. From this figure, we can see the reaction rates are increased due to the increase of acid concentration from 1,2 , and $3 \mathrm{M}$. The result was similar to that reported in Jia and $\mathrm{Li}[1,15]$. A. Mehdilo et.al had reported that acid concentration and treatment time of sulphate process were effecting the growth of $\mathrm{TiO}_{2}[16]$. According to $\mathrm{W}$. Zhang et al. the ilmenite, leucoxene and rutile contains about $40-65 \%$, more than $65 \%$ and $95 \%$ $\mathrm{TiO}_{2}$ respectively [17]. Due to Mahdi, this is because high concentrated sulphuric acid contains more protons $(\mathrm{H}+)$ and sulphate ion, this leads to the increase of leaching rate [11]. The reaction rates at $2 \mathrm{M}$ are higher than for $1 \mathrm{M}$ samples and also show a bit difference for the $3 \mathrm{M}$ samples. Besides that, due to Lane, use of high excessively high acid concentration will not improve the leaching treatment and, moreover, it would cause a heavy burden to the $\mathrm{H}_{2} \mathrm{SO}_{4}$ regeneration system [18]. Therefore, $2 \mathrm{M}$ acid concentration has been chosen for further experimental works.

\subsection{FESEM results}

Figure 2 shows the FESEM images of amorphous $\mathrm{TiO}_{2}$ before calcination and the crystalline $\mathrm{TiO}_{2}$ after calcination process at $650{ }^{\circ} \mathrm{C}$ after treating with 1,2 , and $3 \mathrm{M}$ acid concentration, $80^{\circ} \mathrm{C}$ and $4 \mathrm{~h}$ sulphate process. The growth of amorphous $\mathrm{TiO}_{2}$ is compact to each other in spherical shape with high agglomeration and expected with a low crystallinity. The growth of crystalline $\mathrm{TiO}_{2}$ after calcination process shows the less particles aggregation and smaller amount of agglomeration. We also can see the particle size getting smaller with the average $300 \mathrm{~nm}$

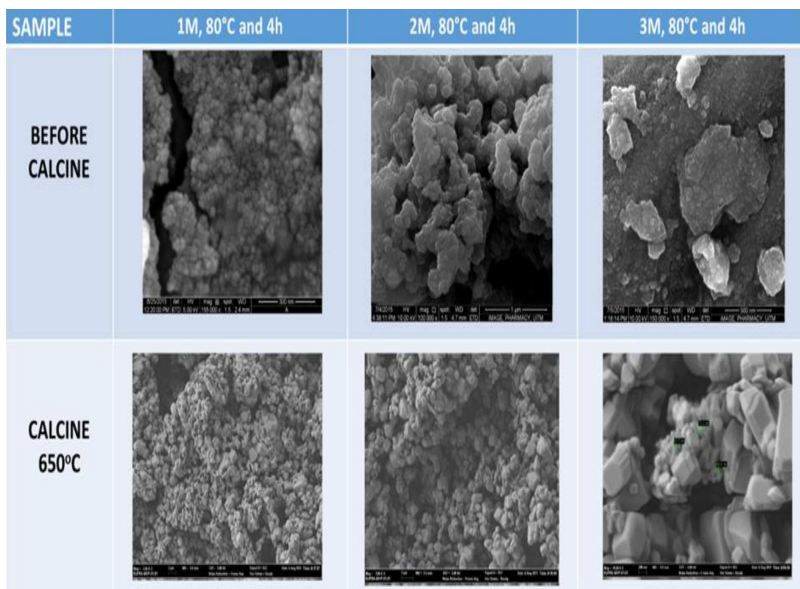

Fig. 2. Amorphous titanium before calcination and crystalline titanium calcinated at $650^{\circ} \mathrm{C}$ after treating with 1,2 , and $3 \mathrm{M}$ acid concentration. Temperature $80^{\circ} \mathrm{C}$ and time $=4 \mathrm{~h}$.

\section{3. $X R D$ results}

Figure 3 shows the XRD results of 1,2 , and $3 \mathrm{M} \mathrm{TiO}_{2}$ after the calcination process at $650^{\circ} \mathrm{C}$. The XRD peak match with titanium dioxide ICSD ref. no. 03-065-5714 (anatase) and 01-086-0147 (rutile). We can see that the crystallinity phase of treated sample after the calcination is quite high compared to phase before calcination 
process. The broad diffraction peaks after the calcination are also higher, meaning that their crystalline size is smaller. From this figure, it is clearly shown that the calcination process affected the crystallinity of $\mathrm{TiO}_{2}$. In this process $2 \mathrm{M}, 80^{\circ} \mathrm{C}$, and $4 \mathrm{~h}$ conditions produce the best results by producing $94.48 \%$ titanium wettage (EDX). The Debye-Scherrer calculations show the produce crystallites average in $20-30 \mathrm{~nm}$ in sizes.

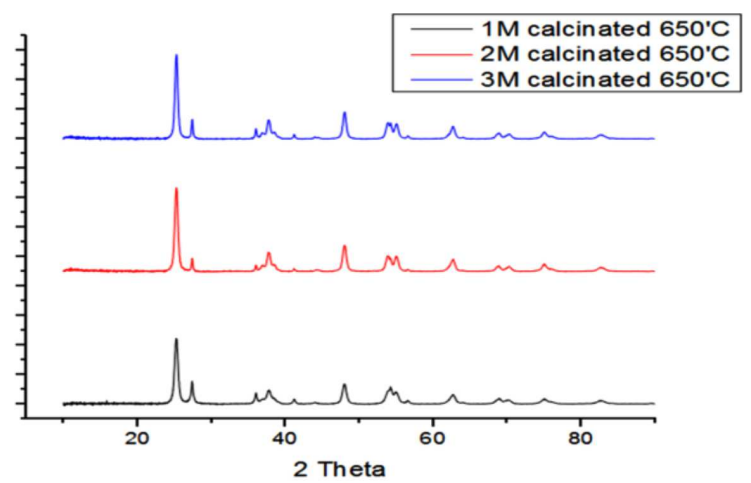

Fig. 3. The XRD results of 1,2 , and $3 \mathrm{M}$ extracted titanium after calcination.

\section{Conclusions}

From the EDX results, the titanium wettage for 1,2 , and $3 \mathrm{M}$ samples shows high increment at $80^{\circ} \mathrm{C}$ compared to their wettage at $70^{\circ} \mathrm{C}$ and $90^{\circ} \mathrm{C}$ temperatures. Characterization with FESEM and XRD shows that clearly the amorphous growths at $2 \mathrm{M}$ and $3 \mathrm{M}$ acid concentration are almost similar and the crystallinity peak is the same. Further experimental works with $2 \mathrm{M}$ acid concentration are chosen for the sake of environment and reducing in preparation cost by producing a lower acidic titanium waste. Hydrothermal method has successfully proven to produce titanium nanocrystals with the average sizes of $20-30 \mathrm{~nm}$. Both acid concentration and temperature affected the $\mathrm{TiO}_{2}$ growth while the calcination process could improve the crystallinity of extracted $\mathrm{TiO}_{2}$.

\section{References}

[1] L. Jia, B. Liang, L. Lü, S. Yuan, L. Zheng, X. Wang, C. Li, Hydrometallurgy 150, 92 (2014).

[2] C. Sasikumar, D.S. Rao, S. Srikanth, B. Ravikumar, N.K. Mukhopadhyay, S.P. Mehrotra, Hydrometallurgy 75, 189 (2004).

[3] M.B. Suwarnkar, R.S. Dhabbe, A.N. Kadam, K.M. Garadkar, Ceram. Int. 40, 5489 (2014).

[4] S. Zhang, M.J. Nicol, Hydrometallurgy 97, 146 (2009).

[5] M. Boutinguiza, J. del Val, A. Riveiro, F. Lusquińos, F. Quintero, R. Comesańa, J. Pou, Phys. Proced. 41, 787 (2013).

[6] Z. Kožáková, M. Mrlík, M. Sedlačík, V. Pavlínek, I. Kuřitka, in: Proc. NanoCon 2011, Brno, Technical University of Ostrava, Ostrava 2011, p. 2.

[7] D. Chen, L. Zhao, Y. Liu, T. Qi, J. Wang, L. Wang, J. Hazard. Mater. 244-245, 588 (2013).

[8] H.H. Ou, S.L. Lo, Sep. Purif. Technol. 58, 179 (2007).

[9] Y. Zhang, T. Qi, Y. Zhang, Hydrometallurgy 96, 52 (2009).

[10] M.S. Meor Yusoff, M.M. Masliana, W. Paulus, P. Devi, M.E. Mahmoud, J. Sci. Technol. 2, 15 (2011).

[11] E.M. Mahdi, M. Hamdi, M.S. Yusoff, P. Wilfred, J. Nano Res. 21, 71 (2013).

[12] M. Mozammel, A. Mohammadzadeh, Measurement 66, $184(2015)$.

[13] S. Zhang, M.J. Nicol, Hydrometallurgy 103, 196 (2010).

[14] R. Razavi, S.M.A. Hosseini, M. Ranjbar, Iran. J. Chem. Chem. Eng.33, 29 (2014).

[15] C. Li, B. Liang, Hydrometallurgy 89, 1 (2007).

[16] A. Mehdilo, M. Irannajad, Physicochem. Probl. Miner. Process. 48, 425 (2012).

[17] W. Zhang, Z. Zhu, C.Y. Cheng, Hydrometallurgy 108, 177 (2011)

[18] D.A. Lane, Directive 89/428, Boston Coll. Int. Comparat. Law Rev. 14, 16 (1991). 